\title{
Syphilis may be a confounding factor, not a causative agent,
}

\section{in syphilitic ALS [version 1; peer review: 2 approved]}

\author{
Bert Tuk ${ }^{1,2}$ \\ ${ }^{1}$ Leiden Academic Center for Drug Research (LACDR), Leiden University, Leiden, 2333 CC, The Netherlands \\ ${ }^{2}$ Ry Pharma, Hofstraat 1, Willemstad, 4797 AC, The Netherlands
}

\section{V1 First published: 02 Aug 2016, 5:1904 \\ https://doi.org/10.12688/f1000research.9318.1}

Latest published: 02 Aug 2016, 5:1904

https://doi.org/10.12688/f1000research.9318.1

\section{Abstract}

Based upon a review of published clinical observations regarding syphilitic amyotrophic lateral sclerosis (ALS), I hypothesize that syphilis is actually a confounding factor, not a causative factor, in syphilitic ALS. Moreover, I propose that the successful treatment of ALS symptoms in patients with syphilitic ALS using penicillin G and hydrocortisone is an indirect consequence of the treatment regimen and is not due to the treatment of syphilis. Specifically, I propose that the observed effect is due to the various pharmacological activities of penicillin G (e.g., a GABA receptor antagonist) and/or the multifaceted pharmacological activity of hydrocortisone. The notion that syphilis may be a confounding factor in syphilitic ALS is highly relevant, as it suggests that treating ALS patients with penicillin $G$ and hydrocortisone-regardless of whether they present with syphilitic ALS or non-syphilitic ALS-may be effective at treating this rapidly progressive, highly devastating disease.

\section{Keywords}

amyotrophic lateral sclerosis , ALS , syphilitic ALS , GABA antagonist , penicillin $\mathrm{G}$, benzylpenicillin , hydrocortisone , circadian rhythm

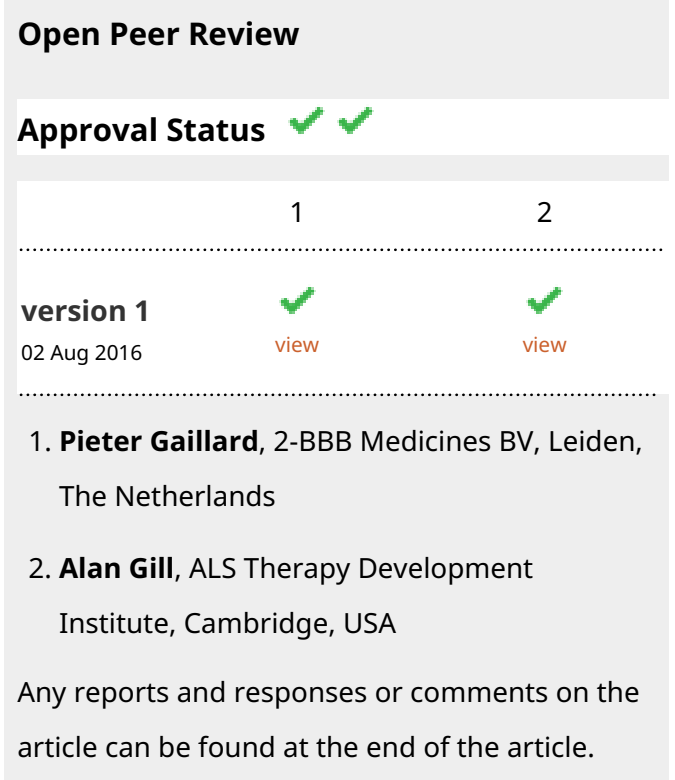

Corresponding author: Bert Tuk (bert.tuk@rypharma.com)

Competing interests: $\mathrm{BT}$ is the inventor on a patent application on the treatment of neuromuscular and neurologic diseases with therapies described in the manuscript, and founded Ry Pharma, a company that aims to develop such therapies.

Grant information: The author(s) declared that no grants were involved in supporting this work.

Copyright: $\odot 2016$ Tuk B. This is an open access article distributed under the terms of the Creative Commons Attribution License, which permits unrestricted use, distribution, and reproduction in any medium, provided the original work is properly cited.

How to cite this article: Tuk B. Syphilis may be a confounding factor, not a causative agent, in syphilitic ALS [version 1; peer review: 2 approved] F1000Research 2016, 5:1904 https://doi.org/10.12688/f1000research.9318.1

First published: 02 Aug 2016, 5:1904 https://doi.org/10.12688/f1000research.9318.1 


\section{Introduction}

Amyotrophic lateral sclerosis (ALS, also known as Lou Gehrig's disease) is a devastating disease with an average post-diagnosis life expectancy of 3-5 years. The clinical manifestations of ALS are well described and include the progressive wasting of muscle mass, reduced muscle coordination, dysphagia, dysarthria, and fatal respiratory depression ${ }^{1-3}$. Several observations regarding the putative pathogenesis of ALS have been reported ${ }^{1-3}$; however, although more than 130 years have passed since it was first described, the pathogenesis of ALS remains poorly understood.

One of the many unresolved mysteries surrounding the pathogenesis of ALS is the presumed association of ALS with syphilis (so-called "syphilitic ALS"). The most puzzling observation in syphilitic ALS is that it is the only form of ALS that has been reported to have been treated effectively; specifically, in 1990 El AlaouiFaris reported five cases of syphilitic ALS in which the patients were followed for 5-13 years after receiving treatment for syphilis ${ }^{4}$. Interestingly, these five reports originated from one neurology center in Morocco. In this center, five patients tested positive for syphilis in their serum and/or cerebrospinal fluid (CSF) and were successfully treated using a specific combination of penicillin $\mathrm{G}$ and hydrocortisone, the standard of care for neurosyphilis in Morocco at the time. Because their ALS symptoms also resolved during treatment, and because these patients no longer tested positive for syphilis, the group concluded that the patients' ALS symptoms were caused by syphilis, and they concluded that neurosyphilis can lead to ALS, giving rise to the syphilitic ALS hypothesis ${ }^{4}$.
Here, I postulate that in countries in which syphilis is highly endemic, syphilis may actually be a confounding factor in syphilitic ALS, and this factor should be considered carefully before drawing conclusions regarding the efficacy of treatment in these populations. Based upon a careful review of the aforementioned five reported cases of syphilitic ALS, I conclude that the only evidence for the existence of syphilitic ALS as a specific disease entity stems from fact that the patients' ALS symptoms resolved simultaneously with the shift from syphilis-positive to syphilis-negative following treatment with penicillin $\mathrm{G}$ and hydrocortisone. Thus, I propose the novel hypothesis that the successful treatment of syphilitic ALS with a specific penicillin $\mathrm{G}$ and hydrocortisone regimen is independent of the treatment of syphilis. Specifically, I propose that the anti-syphilis treatment treated these patients' ALS directly via the off-target pharmacological activity of penicillin $\mathrm{G}$ (e.g., as a GABA receptor antagonist) and/or hydrocortisone.

\section{Case reports of five patients with syphilitic ALS who} were followed for $5-13$ years post-treatment

The five reported cases of treated syphilitic ALS published in 1990 are summarized in Table 1 and Table $2^{4}$. These cases originated from a neurology center in Morocco that was highly experienced in the diagnosis of $\mathrm{ALS}^{4}$. Out of a total of 40 ALS patients who were diagnosed at this neurology center, five were diagnosed with syphilitic ALS. The age at onset of ALS was 27-48 years, and the clinical symptoms included classic features of ALS, including functional impairment of the upper limbs in three patients and spastic paraparesis in two patients ${ }^{4}$. Before receiving treatment, progressive

Table 1. Demographic summary reported cases on syphilitic ALS ${ }^{4}$.

\begin{tabular}{|c|c|c|c|c|c|}
\hline Case & Sex & $\begin{array}{c}\text { Age at syphilis } \\
\text { onset (years) }\end{array}$ & $\begin{array}{c}\text { Age at } \\
\text { ALS } \\
\text { diagnosis } \\
\text { (years) }\end{array}$ & $\begin{array}{c}\text { Treatment } \\
\text { outcome }\end{array}$ & $\begin{array}{c}\text { Follow-up } \\
\text { (years) }\end{array}$ \\
\hline 1 & F & 16 & 39 & Stabilized & 13 \\
\hline 2 & M & No history of syphilis & 37 & Full recovery & 8 \\
\hline 4 & M & unknown & 40 & Good recovery & 8 \\
\hline 5 & M & No history of syphilis & 27 & Good recovery & 5 \\
\hline
\end{tabular}

Table 2. Summary of ALS symptoms in five reported cases of syphilitic ALS ${ }^{4}$.

\begin{tabular}{|l|c|c|c|c|c|}
\hline & Case 1 & Case 2 & Case 3 & Case 4 & Case 5 \\
\hline Upper limb atrophy & + & + & + & + & + \\
\hline Muscle fasciculation & + & + & + & + & + \\
\hline Tongue fasciculation & + & - & - & - & - \\
\hline Muscle cramps & - & + & + & - & + \\
\hline Tendon reflexes & + & + & + & + & + \\
\hline Bulbar symptoms & + & - & - & - & - \\
\hline EMG denervation & + & + & + & + & + \\
\hline Normal motor conduction velocity & + & + & + & + & + \\
\hline Babinski response present & + & - & + & + & - \\
\hline
\end{tabular}




\section{Table 3. 21-day treatment regimen reported to provide long-term reversal of symptoms in syphilitic ALS, when administered every 3 months for four times ${ }^{4}$.}

\begin{tabular}{|c|c|}
\hline Day(s) & $\mathbf{8}$ hour continuous infusion \\
\hline 1 & 1 million units penicillin $\mathrm{G}+100 \mathrm{mg}$ hydrocortisone \\
\hline 2 & 3 million units penicillin $\mathrm{G}+100 \mathrm{mg}$ hydrocortisone \\
\hline 3 & 5 million units penicillin $\mathrm{G}+100 \mathrm{mg}$ hydrocortisone \\
\hline 4 & 10 million units penicillin $\mathrm{G}+100 \mathrm{mg}$ hydrocortisone \\
\hline 5 & 20 million units penicillin $\mathrm{G}+100 \mathrm{mg}$ hydrocortisone \\
\hline $6-14$ & 20 million units penicillin $\mathrm{G}+100 \mathrm{mg}$ hydrocortisone \\
\hline $15-21$ & 20 million units penicillin $\mathrm{G}$ \\
\hline
\end{tabular}

neurological dysfunction had been present from several months to up to 3 years. Two patients also displayed symptoms that are not typically present in ALS patients: patient 3 reported sudden regressive deafness, which was later found to be caused by meningogenic labyrinthitis, and patient 5 had horizontal nystagmus.

\section{Discussion and conclusions regarding syphilitic ALS} Syphilitic ALS is an intriguing phenomenon, as it is the only form of ALS ever reported to have been cured ${ }^{4}$. Moreover, syphilitic ALS has only been reported in Morocco, a country in which syphilis is highly endemic, thereby greatly increasing the likelihood of presenting in patients with ALS. Lastly, neurosyphilis can be a major confounding factor when diagnosing ALS. Therefore, these five case reports of putative syphilitic ALS were reanalyzed in order to explore plausible explanations for these patients' resolution of ALS symptoms.

First, consider the evidence supporting the existence of syphilitic ALS, which stems solely from the observation that ALS symptoms resolved after treatment with penicillin $G$ and hydrocortisone in patients who also tested positive for syphilis. Because a cure for ALS had never been reported, and because penicillin G is an effective treatment for syphilis and neurosyphilis, the authors concluded that these patients had syphilitic ALS. Their reasoning was based on the fact that the treatment regimen-in addition to resolving the patients' ALS symptoms - also treated the patients' latent syphilis infections, as all five patients were negative for syphilis following treatment. Furthermore, the observation that syphilitic ALS has only been reported in Morocco may be explained by the striking fact that at the time, approximately $10 \%$ of the population in Morocco was positive for syphilis ${ }^{5}$. Therefore, these observations appeared to support the notion that syphilis can cause ALS, giving rise to the syphilitic ALS hypothesis.

Here, however, I cast doubt on the notion that syphilitic ALS is a bona fide form of ALS and suggest that syphilis may in fact be a confounding factor. First, if syphilis can cause ALS, one would expect the prevalence of ALS to be higher in countries in which syphilis is highly prevalent. However, this has not been observed. During the period in which the five cases of syphilitic ALS were reported, the prevalence of syphilis was 300-fold higher in Morocco than in developed countries ${ }^{5}$, yet the prevalence of ALS was similar between Morocco and the developed countries.

A second observation is that the ALS symptoms in these five patients either stabilized or resolved after the patients received increasing doses of penicillin $\mathrm{G}$ and hydrocortisone. From this perspective, it is important to note that both penicillin $G$ and hydrocortisone have pharmacological profiles that extend beyond their pharmacotherapeutic applications for treating syphilis. For example, in addition to its antibacterial properties, penicillin $\mathrm{G}$ is also a potent antagonist of GABAergic (i.e., inhibitory) activity ${ }^{6}$ and can induce seizures in patients with renal insufficiency ${ }^{7}$. Interestingly, GABAergic overstimulation was postulated recently to play a role in the pathogenesis of ALS $^{8}$. Furthermore, at sufficient dosages, penicillin $\mathrm{G}$ can affect several major bodily functions and/or systems, including the immune system, the cardiovascular system, metabolic function, renal function, liver function, the hematological system, and the urogenital system ${ }^{7}$.

Similarly, hydrocortisone is a known immunomodulatory and anti-inflammatory agent ${ }^{9}$, thus potentially affecting systems that are involved in the pathogenesis of $\mathrm{ALS}^{1-3}$. Moreover, hydrocortisone has reported efficacy in multiple sclerosis and respiratory diseases ${ }^{9}$, conditions that have clinical overlap with ALS. Furthermore, like penicillin, hydrocortisone can affect several bodily functions and/or systems, including the endocrine system, the immune system, inflammatory function, the respiratory system, the hematological system, and the gastrointestinal system?. Furthermore, hydrocortisone has been reported to affect the GABAergic system ${ }^{10}$, the GABAergic system has been reported to affect the release of cortisone, the natural form of hydrocortisone ${ }^{11}$. and glucocorticoids have been shown to be efficacious in preclinical models for ALS ${ }^{12}$.

A third key observation is that syphilis represents a major confounding factor with respect to the interpretation of clinical outcome, particularly in countries in which syphilis is highly prevalent. The neurology center where the five cases of syphilitic ALS were identified in the 1980s reported that these five patients were identified from a total of 40 patients with ALS. This corresponds to a $12.5 \%$ prevalence of syphilis among ALS patients in this neurology center. Strikingly, this percentage is on par with the prevalence of syphilis in the general population of Morocco (i.e., 10\%) in that same time period ${ }^{5}$. Given this extremely high prevalence, syphilis (particularly neurosyphilis) is likely a confounding factor in the interpretation of many clinical conditions, including neuromuscular diseases such as ALS.

Based on these observations and potential confounding factors, interpreting the clinical outcome in these five patients with syphilitic ALS can lead to incorrect conclusions, unless this treatment is also tested in ALS patients who are negative for syphilis. Given that this has not been attempted, the potential confounding role of syphilis in syphilitic ALS allows for the possibility of alternative explanations. Therefore, I hypothesize that syphilis is actually a confounding factor in syphilitic ALS, and the apparent treatment of syphilitic ALS is actually due to the coincident treatment of both syphilis and ALS due to two separate therapeutic actions of the treatment regimen. I therefore propose that penicillin $\mathrm{G}$ and/or hydrocortisone may be 
effective at treating both syphilitic ALS and non-syphilitic ALS. If correct, this may have long-reaching implications for the treatment of ALS, a currently incurable disease.

Support for this hypothesis comes from a 2013 report of a patient with syphilitic ALS ${ }^{13}$. Given the relatively brief follow-up of this patient (less than one year), this case was not included in the current analysis. However, following a treatment regimen similar to treatment applied in the previous five cases, this patient was reportedly cured of ALS.

Other explanations may also account for the observations discussed above. First, some of the five initial patients who were treated for syphilitic ALS may have been misdiagnosed. However, this is unlikely, given that the neurology center had extensive experience diagnosing both ALS and syphilis ${ }^{4}$. Furthermore, the symptoms associated with $\mathrm{ALS}^{1-3}$ generally do not overlap with the symptoms associated with syphilis ${ }^{5}$. Secondly, it is possible that the patients' ALS symptoms were caused by an infection other than syphilis, and this other infection was treated by the penicillin and hydrocortisone. Moreover, the presence of a previously unidentified infection-and its treatment with penicillin G-may explain the observation that the 21-day treatment (see Table 1) provided long-term reversal of symptoms (i.e., up to 13 years). However, this is unlikely, as it would mean that all five patients had the same infection in addition to testing positive for syphilis. Most importantly, penicillin (a GABA receptor antagonist) may provide long-term treatment of ALS through an action other than its antibacterial activity. Precedence for this hypothesis comes from reports that other GABA receptor antagonists provide longterm effects by resetting the master circadian clock $^{14}$. Moreover, hydrocortisone is also reported to affect circadian rhythm ${ }^{15}$.

In summary, given the published clinical observations, I propose that syphilis may actually be a confounding factor-not a causative agent-in the clinical entity currently called syphilitic ALS. The notion that syphilis may be a confounding factor in syphilitic ALS is highly relevant, as it suggests that treating patients with ALS - regardless of whether they have syphilitic ALS or nonsyphilitic ALS - may be effective at slowing or even reversing the progression of ALS. Based on the rapidly progressive and highly devastating nature of ALS, further research is needed to test this novel hypothesis, possibly leading to the first effective treatment for ALS and perhaps other progressive neuromuscular diseases.

\section{Competing interests}

BT is the inventor on a patent application on the treatment of neuromuscular and neurologic diseases with therapies described in the manuscript, and founded Ry Pharma, a company that aims to develop such therapies.

\section{Grant information}

The author declared that no grants were involved in supporting this work.
1. Kiernan MC, Vucic S, Cheah BC, et al: Amyotrophic lateral sclerosis. Lancet 2011; 377(9769): 942-55

PubMed Abstract | Publisher Full Text

2. Silani V, Messina S, Poletti B, et al:: The diagnosis of Amyotrophic lateral sclerosis in 2010. Arch Ital Biol. 2011; 149(1): 5-27. PubMed Abstract | Publisher Full Text

3. Turner MR, Hardiman O, Benatar M, et al:: Controversies and priorities in amyotrophic lateral sclerosis. Lancet Neurol. 2013; 12(3): 310-22. PubMed Abstract | Publisher Full Text

4. el Alaoui-Faris M, Medejel A, al Zemmouri K, et al.: [Amyotrophic lateral sclerosis syndrome of syphilitic origin. 5 cases.] Rev Neurol (Paris). 1990; 146(1): 41-4. PubMed Abstract

5. Singh AE, Romanowski B: Syphilis: Review with Emphasis on Clinical, Epidemiologic, and Some Biologic Features. Clin Microbiol Rev. 1999; 12(2): 187-209.

PubMed Abstract | Free Full Text

6. Rossokhin AV, Sharonova IN, Bukanova JV, et al: Block of GABA receptor ion channel by penicillin: electrophysiological and modeling insights toward the mechanism. Mol Cell Neurosci. 2014; 63: 72-82. PubMed Abstract | Publisher Full Text

7. Penicillin G summary of product characteristics. Accessed July 16, 2016 . Reference Source

8. Tuk B: Inhibitory system overstimulation plays a role in the pathogenesis of neuromuscular and neurological diseases: a novel hypothesis [version 1 referees: awaiting peer review]. F1000Res. 2016; 5: 1435

Publisher Full Text
9. Hydrocortisone Summary of product characteristics. Accessed July 16, 2016 Reference Source

10. Ong J, Kerr DI, Johnston GA: Cortisol: a potent biphasic modulator at GABAAreceptor complexes in the guinea pig isolated ileum. Neurosci Lett. 1987; 82(1): 101-6.

PubMed Abstract | Publisher Full Text

11. Cullinan WE: GABA receptor subunit expression within hypophysiotropic CRH neurons: a dual hybridization histochemical study. J Comp Neurol. 2000; 419(3): 344-51.

PubMed Abstract | Publisher Full Text

12. Evans MC, Gaillard PJ, de Boer M, et al.: CNS-targeted glucocorticoid reduces pathology in mouse model of amyotrophic lateral sclerosis. Acta Neuropathol Commun. 2014; 2: 66 .

PubMed Abstract | Publisher Full Text | Free Full Text

13. Chraa M, Mebrouk Y, McCaughey C, et al:: Amyotrophic lateral sclerosis mimic syndrome due to neurosyphilis. Amyotroph Lateral Scler Frontotemporal Degener. 2013; 14(3): 234.

PubMed Abstract | Publisher Full Text

14. Ruby NF, Hwang CE, Wessells $C$, et al:: Hippocampal-dependent learning requires a functional circadian system. Proc Natl Acad Sci U S A. 2008; 105(40): 15593-8. PubMed Abstract | Publisher Full Text | Free Full Text

15. Chan S, Debono M: Replication of cortisol circadian rhythm: new advances in hydrocortisone replacement therapy. Ther Adv Endocrinol Metab. 2010; 1(3): 129-138 PubMed Abstract | Publisher Full Text | Free Full Text 


\title{
Open Peer Review
}

\section{Current Peer Review Status:}

\section{Version 1}

Reviewer Report 21 October 2016

https://doi.org/10.5256/f1000research.10034.r16950

(C) 2016 Gill A. This is an open access peer review report distributed under the terms of the Creative Commons Attribution License, which permits unrestricted use, distribution, and reproduction in any medium, provided the original work is properly cited.

\author{
Alan Gill \\ ALS Therapy Development Institute, Cambridge, MA, USA

\section{Introduction}

The antecedent hypothesis for this work might be summarized in this way: excitatory overstimulation is a homeostatic response to inhibitory overstimulation. What is actually needed is to reduce inhibitory activity (the primary problem) so compensatory excitatory overstimulation is no longer required.

Given the widely accepted working model that reduced inhibitory and excessive excitatory neuronal activity contributes to ALS through neuronal excitotoxicity, the hypothesis asks that we look at ALS with new eyes. In this devastating disease for which we have no satisfactory treatment, looking with new eyes is certainly warranted.

The current work provides evidence that co-treatment with PENG and hydrocortisone beneficially slows ALS progression, even in ALS patients that did not have syphilis. The current work's hypothesis might be summarized in this way: PENG helps ALS symptoms because it is a GABA receptor antagonist. Hydrocortisone helps with inflammation also present in ALS.

Apart from the limitations of our understanding ALS pathology, the current work opens an array of complexities, including regulatory interneuron networks, inhibitory receptor subtypes, antagonist drug properties and side-effects, neuronal ion channel composition, neuropeptide modulation, central pattern generator function, and neuroinflammation. For example, why tiptoe into GABA antagonism with PENG when more refined and specific inhibitors are available. Or, patient-to-patient variability in blood-brain barrier leakiness could make it difficult to control CNS PENG levels and the probability of seizure induction. Or, should somatostatin-expressing interneuron networks be selected for in our treatment approach? Should studies include cohorts that do not receive hydrocortisone, or only hydrocortisone? Combination drug studies, if anything is to be learned from them, require expensive designs that test each drug separately and the identification of a basis for doses used in the combination, or combinations. 
The complexity is formidable. But in the end, what is really important is whether PENG plus hydrocortisone actually slows ALS progression, i.e. "does it work?". Even if we don't understand why we have an obligation to try what works. The true purpose of understanding the complexities above is to try to design a reliable therapeutic regimen for clinical application. We want the therapy to work predictably and we don't want it to do harm.

The comments and references that I have compiled below are intended to stimulate the process of making the potential therapy safe and predictable.

\section{Comments and References:}

The outcome of homeostatic regulation depends on the complement of ion channels expressed in cells: in some cases, loss of specific ion channels can be compensated; in others, the homeostatic mechanism itself causes pathological function ${ }^{1}$.

There may be a need to target restricted GABAergic subpopulations and cell types characterized by distinct laminar location, morphology, axonal projection, and electrophysiological properties ${ }^{2}$.

\section{Increasing GABA May Be Helpful}

The GABA analog Pregabalin increases extracellular GABA by inducing its synthesis and transport. Cacna2d2, the gene encoding the Alpha2delta2 subunit of voltage-gated calcium channels (VGCCs), is a developmental switch that limits axon growth and regeneration. In vivo, Alpha2delta2 pharmacological blockade through Pregabalin administration enhanced axon regeneration in adult mice after spinal cord injury. Since Pregabalin is already an established treatment for a wide range of neurological disorders, targeting Alpha2delta2 may be a novel treatment strategy to promote structural plasticity and regeneration following CNS trauma ${ }^{3}$.

Electrophysiological and histological studies support the pathophysiological concept of an impaired inhibitory, namely GABAergic, control of the motoneurons in the cerebral cortex of ALS patients. However, in the prefrontal and temporal cortex of ALS patients the GABA synthesizing enzyme glutamic acid decarboxylase (GAD) was significantly upregulated ${ }^{4}$.

There are reduced levels of GABA in the motor cortex of patients with ALS. Patients with ALS had significantly lower levels of GABA in the motor cortex than did healthy controls. Riluzole-naive patients with ALS had higher levels of glutamate-glutamine than did riluzole-treated patients with ALS or healthy controls ${ }^{5,6}$.

\section{Increasing Glycinergic Function May Be Helpful}

The selective loss of inhibitory glycinergic regulation of motoneuron function or glycinergic interneuron degeneration contributes to motoneuron degeneration in amyotrophic lateral sclerosis 7 .

Anti-glutamate drugs don't have major disease-modifying effects clinically in ALS. Nevertheless, hyperexcitability of upper and lower motor neurons is a feature of human ALS and transgenic (tg) mouse models of ALS. Motor neuron excitability is modulated by presynaptic glycinergic and GABAergic innervation and postsynaptic glycine and GABA(A) receptors that mediate synaptic 
inhibition. Inhibitory glycinergic innervation of spinal motor neurons becomes deficient before motor neuron degeneration is evident in G93A-hSOD1 mice. GABAergic innervation of ALS mouse motor neurons and GABA(A) receptor function appear normal. Abnormal synaptic inhibition resulting from dysfunction of interneurons and motor neuron Glycine receptors may participate in ALS pathogenesis ${ }^{8}$.

Muscle paralysis during REM sleep requires activation of both GABA and glycine receptors together. Glycine alone doesn't paralyze the muscles; GABA is also required. To prevent muscle paralysis during REM sleep both types of receptors have to be off. GABA antagonists like bicuculline, metrazol, and flumazenil would remove the GABA effect and reverse paralysis, stimulating muscle movement. In general these drugs produce stimulant and convulsant effects, and are mainly used for counteracting overdoses of sedative drugs. There is no clear way to direct their activity in a specific direction to solve ALS paralysis. GABA interneurons are part of most neuronal networks in the brain and spinal cord. They act to modulate activity through the networks and they do so by monitoring activity level and responding to the level in a way that keeps it within normal limits. They participate in rhythm and pattern generating networks that coordinate many kinds of brain and spinal cord activity, including breathing and movement.

GABA loss seems to be less influential than glycine loss. In mice lacking physiological levels of GABA, there are distinct regional changes in motor neuron number and muscle innervation, which appear to be linked to their physiological function and to their rostral-caudal position within the developing spinal cord. For more caudal (lumbar) regions of the spinal cord, the effect of GABA is less influential on motor neuron development compared to that of glycine ${ }^{9}$.

GABA(A) and glycine receptors are the major inhibitory neurotransmitter receptors and contribute to many synaptic functions. Gephyrin promotes recruitment of GABA(A) receptors instead of glycine receptors. This mechanism could affect the balance of GABA(A) vs. glycine in ALS ${ }^{10}$.

Reduced short interval intracortical inhibition that leads to development of cortical hyperexcitability in ALS represents degeneration of inhibitory cortical circuits, combined with excessive excitation of high threshold excitatory pathways. Neuroprotective strategies aimed at preserving the integrity of intracortical inhibitory circuits, in addition to antagonizing excitatory cortical circuits, may provide novel therapeutic targets in $\mathrm{ALS}^{11}$.

"A wide range of evidence from clinical, histological, genetic, neurophysiological, neuroimaging and neuropsychological studies, suggests that a loss of central nervous system inhibitory neuronal influence is a contributing factor in ALS pathogenesis. This loss of inhibitory function points intuitively to an 'interneuronopathy', with natural differences in cortical and spinal inhibitory networks reflected in the hitherto unexplained variable compartmentalization of pathology within upper and lower motor neuron populations. An excitotoxic final common pathway might then result from unopposed glutamatergic activity. If correct, therapies aimed specifically at supporting interneuronal function may provide a novel therapeutic strategy." ${ }^{12}$.

Along with GABA and glycine, the coexpressed interneuron neuromodulatory peptides, like somatostatin, VIP, CCK, and parvalbumin have major influences on the network functions and channel expression. Other neuropeptides also contribute to the complexity. a-MSH preserves GAD67 expression and prevents loss of the somatostatin-expressing subtype of GABAergic GAD67+ inhibitory interneurons ${ }^{13}$. 


\section{GABAergic Interneurons Contribute to Central Pattern Generators}

Well controlled pharmacologic manipulation of GABAergic networks may be difficult.

Central pattern generators are neuronal circuits that when activated can produce rhythmic motor patterns such as walking, breathing, flying, and swimming in the absence of sensory or descending inputs that carry specific timing information ${ }^{14}$.

A class of GABAergic sensory neurons contacting the CSF in the vertebrate spinal cord are referred to as CSF-cNs. These cells modulate components of locomotor central pattern generators. CSF-cNs form active GABAergic synapses onto V0-v glutamatergic interneurons, an essential component of locomotor Central Pattern Generators. Spinal GABAergic sensory neurons can tune the excitability of locomotor Central Pattern Generators in a state-dependent manner by projecting onto essential components of the excitatory premotor pool ${ }^{15}$.

Motor neurons themselves can control, by retrograde transmission, upstream glutamatergic V2a interneurons that drive locomotion ${ }^{16}$.

The lumbar central pattern generator for locomotion selectively modulates the intracellular activity of spinal respiratory neurons engaged in expiration. Medullary respiratory network activity of both thoracolumbar expiratory motor neurons and interneurons is rhythmically modulated with hindlimb ipsilateral flexor locomotor activity. Locomotion and respiration must to be tightly coordinated to reduce muscular interferences and facilitate breathing rate acceleration during exercise $^{17}$.

\section{Conclusion}

The question remains. Can we identify a safer, more predictable, therapeutic regimen than PENG/Hydrocortisone by trying to understand which inhibitory interneuron networks require interventions and which do not? And which specific antagonist (or agonist) drugs would optimize our test of the hypothesis? Can specific peptide neuromodulators contribute to improving the regimen? These considerations do not preclude the importance of carefully testing the PENG/Hydrocortisone regimen itself. The complexity of this task alone is significant. Refinements of the regimen only add complexity, but may make the difference between safe, practical use in ALS and early rejection of the approach.

\section{References}

1. O'Leary T, Williams AH, Franci A, Marder E: Cell types, network homeostasis, and pathological compensation from a biologically plausible ion channel expression model.Neuron. 2014; 82 (4): 809-21 PubMed Abstract | Publisher Full Text

2. He M, Tucciarone J, Lee S, Nigro MJ, et al.: Strategies and Tools for Combinatorial Targeting of GABAergic Neurons in Mouse Cerebral Cortex.Neuron. 2016; 91 (6): 1228-43 PubMed Abstract | Publisher Full Text

3. Tedeschi A, Dupraz S, Laskowski CJ, Xue J, et al.: The Calcium Channel Subunit Alpha2delta2 Suppresses Axon Regeneration in the Adult CNS.Neuron. 2016; 92 (2): 419-434 PubMed Abstract | Publisher Full Text

4. Petri S, Kollewe K, Grothe $\mathrm{C}$, Hori A, et al.: GABA(A)-receptor mRNA expression in the prefrontal 
and temporal cortex of ALS patients.J Neurol Sci. 2006; 250 (1-2): 124-32 PubMed Abstract | Publisher Full Text

5. Foerster BR, Pomper MG, Callaghan BC, Petrou M, et al.: An imbalance between excitatory and inhibitory neurotransmitters in amyotrophic lateral sclerosis revealed by use of 3-T proton magnetic resonance spectroscopy.JAMA Neurol. 2013; 70 (8): 1009-16 PubMed Abstract | Publisher Full Text

6. Nieto-Gonzalez JL, Moser J, Lauritzen M, Schmitt-John T, et al.: Reduced GABAergic inhibition explains cortical hyperexcitability in the wobbler mouse model of ALS.Cereb Cortex. 2011; 21 (3): 625-35 PubMed Abstract | Publisher Full Text

7. Chang Q, Martin LJ: Glycinergic innervation of motoneurons is deficient in amyotrophic lateral sclerosis mice: a quantitative confocal analysis.Am J Pathol. 2009; 174 (2): $574-85$ PubMed Abstract | Publisher Full Text

8. Martin LJ, Chang Q: Inhibitory synaptic regulation of motoneurons: a new target of disease mechanisms in amyotrophic lateral sclerosis.Mol Neurobiol. 2012; 45 (1): 30-42 PubMed Abstract | Publisher Full Text

9. Fogarty MJ, Smallcombe KL, Yanagawa Y, Obata K, et al.: Genetic deficiency of GABA differentially regulates respiratory and non-respiratory motor neuron development.PLoS One. 2013; 8 (2): e56257 PubMed Abstract | Publisher Full Text

10. Maric HM, Kasaragod VB, Hausrat TJ, Kneussel M, et al.: Molecular basis of the alternative recruitment of GABA(A) versus glycine receptors through gephyrin.Nat Commun. 2014; 5: 5767 PubMed Abstract | Publisher Full Text

11. Vucic S, Cheah BC, Kiernan MC: Defining the mechanisms that underlie cortical hyperexcitability in amyotrophic lateral sclerosis.Exp Neurol. 2009; 220 (1): 177-82 PubMed Abstract | Publisher Full Text

12. Turner MR, Kiernan MC: Does interneuronal dysfunction contribute to neurodegeneration in amyotrophic lateral sclerosis?. Amyotroph Lateral Scler. 2012; 13 (3): 245-50 PubMed Abstract | Publisher Full Text

13. Ma K, McLaurin J: a-Melanocyte stimulating hormone prevents GABAergic neuronal loss and improves cognitive function in Alzheimer's disease.J Neurosci. 2014; 34 (20): 6736-45 PubMed Abstract | Publisher Full Text

14. Marder E, Bucher D: Central pattern generators and the control of rhythmic movements. Current Biology. 2001; 11 (23): R986-R996 Publisher Full Text

15. Fidelin K, Djenoune L, Stokes C, Prendergast A, et al.: State-Dependent Modulation of Locomotion by GABAergic Spinal Sensory Neurons.Curr Biol. 2015; 25 (23): 3035-47 PubMed Abstract | Publisher Full Text

16. Song J, Ampatzis K, Björnfors ER, El Manira A: Motor neurons control locomotor circuit function retrogradely via gap junctions.Nature. 2016; 529 (7586): 399-402 PubMed Abstract | Publisher Full Text

17. Le Gal JP, Juvin L, Cardoit L, Morin D: Bimodal Respiratory-Locomotor Neurons in the Neonatal Rat Spinal Cord.J Neurosci. 2016; 36 (3): 926-37 PubMed Abstract | Publisher Full Text

Competing Interests: No competing interests were disclosed.

I confirm that I have read this submission and believe that I have an appropriate level of expertise to confirm that it is of an acceptable scientific standard.

Reviewer Report 22 August 2016 


\section{https://doi.org/10.5256/f1000research.10034.r15388}

(C) 2016 Gaillard P. This is an open access peer review report distributed under the terms of the Creative Commons Attribution License, which permits unrestricted use, distribution, and reproduction in any medium, provided the original work is properly cited.

\section{Pieter Gaillard}

\section{2-BBB Medicines BV, Leiden, The Netherlands}

Dr Bert Tuk has provided the readers with a fascinating Opinion Article, in which he sets out his hypothesis that syphilitic ALS is actually not caused by syphilis. And as a result, the pharmacotherapy that was used to treat and cure the confounding syphilitic origin of the ALS symptoms may offer the first effective treatment option for patients suffering from the fatal disease ALS, be it with or without the presence of syphilis.

This Opinion Article builds on the earlier presented Opinion Article in this journal by Dr. Tuk, entitled: Inhibitory system overstimulation plays a role in the pathogenesis of neuromuscular and neurological diseases: a novel hypothesis ${ }^{1}$. In this paper he discloses his assessment of a fundamentally new view of how the symptoms of ALS could be caused, essentially by an overstimulation of the GABA neurotransmitter system, and his current paper basically provided case study proof of concept for this hypothesis with a specific treatment regimen of existing drugs (penicillin $\mathrm{G}$ and hydrocortisone) that may indeed act to normalise this overstimulated GABA neurotransmitter system.

The methods and analysis of the existing literature and data are sound, as is the discussion leading to the new hypothesis, although a more direct link and explanation to the suggested mechanism (modification of the overstimulation of the GABA neurotransmitter system) would have been helpful to the reader.

And a few more words of caution could have been added to the discussion section, since this work will likely result in a "call to action" by patients and their treating physicians. It is therefore important to advise to keep tight involvement of expert (clinical) pharmacologists, neurologists, and neuroscientists as it is yet unknown what the impact of any modification to this specific treatment regimen would do to an individual patient. Today we don't know how strict the applied pharmacotherapeutic regimen is to render the expected effect. Can the regimen be modified, or improved? Will modification in the regimen result in any effects on tolerance development, or perhaps sensitization, with risk of seizure activity? How will the two drugs (penicillin G and hydrocortisol) interact when the regimen is modified? Can other compounds be used with a similar pharmacologic profile? Definitely one cannot simply replace to other antibiotics, like minocycline, which was proven effective as alternative in treating neurosyphilis ${ }^{2}$, yet in ALS patients proven to be detrimental ${ }^{3}$, perhaps - according the hypothesis of Dr. Tuk -because minocycline has GABA agonistic properties ${ }^{4}$. Many key questions that deserve careful consideration, monitoring and further studies. Other domains that require further attention is the role of the bulbar onset and treatment effect, since this patient seemed less responsive. And since the two drugs effect two interconnected major systems in the body simultaneously (penicillin $\mathrm{G}$ on the inhibitory neurotransmitter system and hydrocortisol on the endocrinology system, both centrally and systemically), there is a world of knowledge to be gained in ALS and also other related diseases how this interaction will play out, leading to hopefully to the long awaited 
improvements for these devastating brain diseases.

\section{References}

1. Tuk B: Overstimulation of the inhibitory nervous system plays a role in the pathogenesis of neuromuscular and neurological diseases: a novel hypothesis. F1000Research. 2016; 5. Publisher Full Text

2. De Maria A, Solaro C, Abbruzzese M, Primavera A: Minocycline for symptomatic neurosyphilis in patients allergic to penicillin.N Engl J Med. 1997; 337 (18): 1322-3 PubMed Abstract | Publisher Full Text

3. Gordon PH, Moore DH, Miller RG, Florence JM, et al.: Efficacy of minocycline in patients with amyotrophic lateral sclerosis: a phase III randomised trial.Lancet Neurol. 2007; 6 (12): 1045-53 PubMed Abstract | Publisher Full Text

4. Ahmadirad N, Shojaei A, Javan M, Pourgholami MH, et al.: Effect of minocycline on pentylenetetrazol-induced chemical kindled seizures in mice.Neurol Sci. 2014; 35 (4): 571-6 PubMed Abstract | Publisher Full Text

Competing Interests: No competing interests were disclosed.

I confirm that I have read this submission and believe that I have an appropriate level of expertise to confirm that it is of an acceptable scientific standard.

The benefits of publishing with F1000Research:

- Your article is published within days, with no editorial bias

- You can publish traditional articles, null/negative results, case reports, data notes and more

- The peer review process is transparent and collaborative

- Your article is indexed in PubMed after passing peer review

- Dedicated customer support at every stage

For pre-submission enquiries, contact research@f1000.com 